\title{
BMJ Open Exploring newly qualified doctors' workplace stressors: an interview study from Australia
}

\author{
Victoria R Tallentire, ${ }^{1}$ Samantha E Smith, ${ }^{1}$ Adam D Facey, ${ }^{2}$ Laila Rotstein ${ }^{2}$
}

To cite: Tallentire VR, Smith SE, Facey AD, et al. Exploring newly qualified doctors' workplace stressors: an interview study from Australia. BMJ Open 2017;7:e015890. doi:10.1136/ bmjopen-2017-015890

- Prepublication history for this paper is available online. To view these files, please visit the journal online (http://dx.doi. org/10.1136/bmjopen-2017015890).

Received 12 January 2017 Revised 20 May 2017 Accepted 8 June 2017

\section{CrossMark}

${ }^{1}$ University of Edinburgh, Edinburgh, UK

${ }^{2}$ Alfred Health, Melbourne, Victoria, Australia

Correspondence to Dr. Victoria R Tallentire; Vicky.Tallentire@ed.ac.uk

\section{ABSTRACT}

Purpose Postgraduate year 1 (PGY1) doctors suffer from high levels of psychological distress, yet the contributory factors are poorly understood. This study used an existing model of workplace stress to explore the elements most pertinent to PGY1 doctors. In turn, the data were used to amend and refine the conceptual model to better reflect the unique experiences of PGY1 doctors.

Method Focus groups were undertaken with PGY1 doctors working at four different health services in Victoria Australia. Transcripts were coded using Michie's model of workplace stress as the initial coding template. Remaining text was coded inductively and the supplementary codes were used to modify and amplify Michie's framework.

Results There were 37 participants in total. Key themes included stressors intrinsic to the job, such as work overload and long hours, as well as those related to the context of work such as lack of role clarity and relationships with colleagues. The main modification to Michie's framework was the addition of the theme of uncertainty. This concept related to most of the preexisting themes in complex ways, culminating in an overall sense of anxiety.

Conclusions Michie's model of workplace stress can be effectively used to explore the stressors experienced by PGY1 doctors. Pervasive uncertainty may help to explain the high levels of psychological morbidity in this group. While some uncertainty will always remain, the medical education community must seek ways to improve role clarity and promote mutual respect.

\section{INTRODUCTION}

It has been recognised for many years that medical professionals are at high risk of depression, substance abuse, burnout and suicide. ${ }^{1-4}$ A recent Australian study aiming to quantify the prevalence of psychological distress (an umbrella term encompassing stress, burnout, depression, anxiety and related mental health problems) concluded that doctors report substantially higher rates of 'very high' psychological distress than other professions. ${ }^{5}$ Furthermore, it showed that the prevalence of very high psychological distress among doctors aged 30 and below is over 10 times greater than the corresponding prevalence among other professionals of

\section{Strengths and limitations of this study}

This study used the principles of template analysis to produce a bespoke version of a pre-existing workplace stress model that encapsulates the stressors applicable to postgraduate year 1 (PGY1) doctors.

- It builds on the literature relating to occupational stress and addresses the shortcomings of previous work by using a robust conceptual framework to provide theoretical insight and using interviewbased methods to allow deep exploration of contributory factors.

- It is limited by the fact it did not use direct observation of participants in the workplace, instead relying on retrospective accounts and reflections.

- The participants were limited to PGY1 doctors working in four hospitals within a single Australian state.

While focus groups benefit from allowing participants to discuss ideas and react to the suggestions and experiences of others, it is likely that this forum limited the willingness of PGY1 doctors to discuss either individual personality traits that may predispose to stress or the impact of work-related stress on their personal lives.

the same age. ${ }^{5}$ While it is possible that selection bias of those with personality traits which predispose to psychological distress may contribute to the stark differences in mental health status between doctors and other professionals, additional evidence suggests this may not be the case. Brazeau et al recently published a multicentre study demonstrating that at matriculation, US medical students had significantly lower rates of psychological morbidity than age-matched students from other courses. ${ }^{1}$ Honney et al focused on students during completion of their degrees and found significantly higher levels of moderate or severe depression among life sciences students compared with medical students. ${ }^{6}$ It would seem, therefore, that the selection of predisposed individuals into medicine does not sufficiently account 
for the profession's unparalleled levels of psychological distress.

It has been repeatedly concluded that the transition from study to work appears to be challenging and stressful, ${ }^{57}$ and the first postgraduate year is the time of greatest distress. ${ }^{8}$ A recent systematic literature review by Facey et al identified 17 studies exploring the factors contributing to psychological distress in postgraduate year 1 (PGY1) doctors. ${ }^{9}$ It concluded that factors relating to a PGY1 doctor's role within the healthcare organisation are a significant source of stress. The authors also noted that the complex interaction of stressors with personality traits of individual doctors seemed to be of pivotal importance, and should be considered in future work. However, many of the studies were of poor quality, lacked the theoretical insight provided by a robust conceptual framework and employed a questionnaire-based design, limiting deep exploration of the factors identified. This study therefore aimed to address the gap in the literature: the exploration of the factors contributing to psychological distress of PGY1 doctors using a robust conceptual framework to provide theoretical insight and improved understanding.

\section{Conceptual framework}

To build on the substantial body of literature relating to occupational stress (mostly conducted in fields other than medicine), this study uses the conceptual typologies provided by Michie and Murphy. ${ }^{11}$ Murphy categorised work-related stressors into those originating from the content of work and those stemming from the context of work. ${ }^{11}$ Content stressors relate to characteristics of the job (such as workload) that cause a misalignment between the demands placed on an individual and their ability to cope with such demands. Context stressors relate to the broader aspects of work such as an individual's role in the organisation, their career development opportunities, relationships at work and the organisational climate. ${ }^{11}$ Murphy's model was subsequently reframed by Michie to emphasise the unique interplay between an individual and the characteristics of their work (as described by Murphy) in the generation of work-related stress. ${ }^{10}$ This contemporary view of occupational stress thereby acknowledges individual variation in response to stress, a factor identified as important in relation to PGY1 doctors in Facey et al's recent review. ${ }^{9}$ It also incorporates the increasingly recognised impact of work-related stress on extraorganisational aspects such as family life and leisure time. ${ }^{10} 12$ As well as being research informed and widely accepted, Michie's model resonates with the beliefs and understanding of the research team, and was therefore chosen to provide the conceptual foundation for this study.

\section{Research questions}

Informed by the literature and the conceptual models described above, and approached from a constructivist perspective, this study aimed to answer the following questionsRousseau CL:
1. In what ways, and to what extent, is Michie's model of workplace stress applicable to PGY1 doctors?

2. In what ways could Michie's model be amended or refined to reflect the specific stressors experienced by PGY1 doctors?

\section{METHOD}

Setting

The study was conducted in Victoria, Australia where newly qualified doctors undertake a 1-year internship period immediately following graduation from medical school. Satisfactory completion of internship leads to general registration. The Postgraduate Medical Council of Victoria mandates that PGY1 doctors (colloquially referred to as 'interns') gain experience of emergency medical care, medicine and surgery, with the remaining time spent in 'non-core' rotations in hospital or community-based care. ${ }^{13}$

\section{Sampling}

The chief medical officers, or their equivalent, at a variety of health services throughout Victoria were contacted by email with an explanation of the project. From the positive respondents, a purposive sampling technique was used to select four health services for inclusion in the study: Alfred Health (The Alfred Hospital), Melbourne Health (Royal Melbourne Hospital), Monash Health (Monash Medical Centre) and Ballarat Health Services (Ballarat Base Hospital). The purposive sampling technique included selection of both metropolitan and regional hospitals as well as academic and non-academic centres. At each of the selected sites, locally based PGY1 doctors were contacted by email with an explanation of the study and an invitation to participate. Attendance by PGY1 doctors was entirely voluntary.

\section{Data collection}

Between August and November 2014, four focus groups (one at each location) were facilitated by a single researcher (VT). A second researcher (AF or LR) was present to obtain consent, take field notes and ensure adequate recording. All PGY1 doctors had been in post for at least 6 months and were therefore familiar with the demands, expectations and stressors of the role. The use of focus groups diluted the power gradient between the researcher and the 'researched' and facilitated deep exploration of issues by promoting discussion between participants. ${ }^{14}$ Written consent for the recording of the focus groups and the publication of anonymised results was obtained from all participants. Each focus group was semistructured in nature, initiated with a number of open questions based on Michie's model of workplace stress. ${ }^{10}$ The use of an 'a priori' approach to data collection and analysis explicitly allowed pre-existing theory to inform the data. Questions relating to each of Michie's major categories (such as 'intrinsic to job', 'role organisation' etc) were used to initiate discussion. However, participants 
were encouraged to reflect on their own experiences and discussion progressed to being free flowing and unstructured. At that stage, deeper exploration of topics was encouraged by the facilitator through the identification of inconsistencies between participants and requests for clarification and examples. ${ }^{14} 15$ Through the process of free-flowing conversation, the data collected and analysed could, in turn, be used to inform pre-existing theory.

\section{Analysis}

The focus group recordings were transcribed verbatim and analysis was conducted using the transcripts with reference to audio recordings and field notes when clarification of meaning was required. The transcribed data were coded independently by two researchers (VT and SS), both practising clinicians and experienced qualitative researchers. Each sentence or excerpt was coded using Michie's conceptual model as the initial coding 'template' (theory informing the data). ${ }^{16}$ To preserve the richness of the data, excerpts which could not be coded into the pre-existing framework were coded inductively. The supplementary codes were then used to modify and amplify Michie's model though an iterative process of discussion between researchers and comparison of data within and between focus groups (data informing the theory). New themes were reshuffled and redefined until agreement was reached between researchers (VT and SS). Through this process, an additional, overarching theme became evident, as described below.

\section{Ethics}

Ethical approval was granted by the Monash University Human Resources Ethics Committee.

\section{RESULTS}

Four focus groups lasting between 46 and 65 min were undertaken with a total of 37 participants ( 7 to 14 per group). The quotes used below are identified using two numbers-the first relates to the focus group the PGY1 doctor attended (from 1 to 4 ) and the second number is the unique identifier for a particular individual in each group. Further illustrative quotes are provided in table 1. The following themes, resonating with various aspects of Michie's model, were identified:

\section{Intrinsic to job}

PGY1 doctors cited several factors related to the volume of work and working environment that influenced their levels of stress. Specifically, they discussed the stress related to work overload.

...you're covering about 100 patients on your own and it's just, your pager is full. Like, you've got 25 outstanding pages, a few MET [medical emergency team] calls going, like, really sick patients. And it's just that absolute sense of being totally overwhelmed and exhausted... (2:5)
The long hours and heavy workload resulted in disruption to normal routines of eating and sleeping, with PGY1 doctors emphasising the problems they had attending to even the most basic of needs during working hours.

...it's like really exhausting, because I couldn't get to bed at my normal time and I found it really hard to figure out when to eat to start with as well, and drink actually. Drinking was harder than eating. I think being dehydrated and tired has been the hardest part. (2:3)

\section{Role in organisation}

PGY1 doctors spoke extensively about the stress associated with their role, in particular the challenges associated with their new level of responsibility and the requirement to make autonomous clinical decisions.

Having to take responsibility and make the decisions, by myself [was stressful]. Even though there was support there, it's that realisation that really kind of hit home, it was just overwhelming. (2:1)

In addition to the responsibility of clinical decisions, PGY1 doctors also found it difficult to know exactly what was expected of them and understand the specific components of their role.

....at no stage was there any; 'this is what I expect of you' in any rotation... there was never that formal: 'I expect you to do this, I don't expect you to do that, I expect you to be here or not be here'. There was more of, see what's happening and sort of learn by trial and error. (4:7)

...you get the nurses saying 'well how come you haven't done this? How come you haven't done that?' We're, like, 'we didn't know we were supposed to do that'. (1:1)

\section{Career development}

For PGY1 doctors, stress is generated by the requirement for good references from senior colleagues, a perceived lack of job security and the feeling of 'constant applications'.

It's odd that it's only a single year contract [of employment]. Like it creates a perennial, like a yearly stress that potentially could be avoided... (1:5)

...you just have to keep applying. You just don't have time to kind of stop and think about what you want to do. $(2: 3)$

The PGY1 doctors expressed concerns about longer term career aspirations including the scarcity of places on specialty training schemes and the possibility of being unable to pursue their career of choice.

I think there's a lot of pressure now to kind of get through and get into specialty training, just because there are so many graduates coming through now, there's a bit of a bottle neck. I certainly feel pressure 


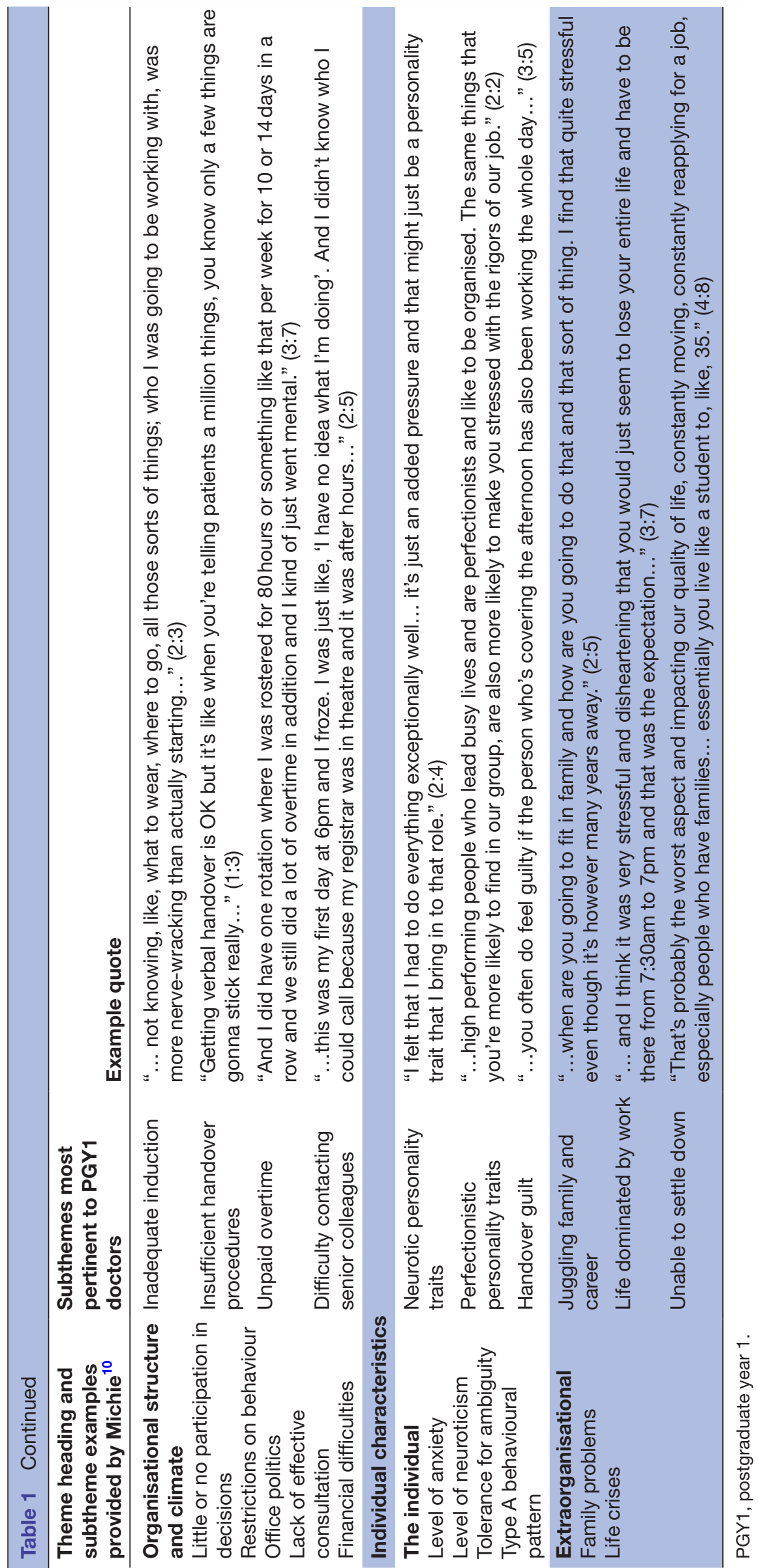


that you've got to make a decision early and kind of choose your stream and go down that path... (2:5)

\section{Relationships at work}

While peers were most often cited as a source of support, relationships with senior colleagues were often a source of stress, with some registrars described by PGY1 doctors as 'outrageously cruel' and 'terrifying'. They felt that there was a lack of appreciation and respect from seniors, described being 'yelled at' and said that such experiences made them more reluctant to seek senior help in the future.

I didn't know what I was doing and I called the registrar to ask for help and he said, 'I don't want to deal with this, you sort it out' and hung up on me. And it's, like, absolutely terrifying. It was my first week. I had no idea what I was doing with this patient... It's not professional the way we're spoken to sometimes, and, you know, it wouldn't be allowed in any other workplace so it shouldn't be allowed here. (2:6)

While sometimes a source of great support, relationships with nursing staff could also be a significant source of stress. PGY1 doctors worried that nurses would make them look lazy or unhelpful to other staff (usually by writing damaging statements in patient notes) and that they had unrealistic expectations of PGY1 doctors, particularly regarding the speed at which pagers could be answered.

I find sometimes the documentation that the nurses write can be quite vindictive; 'paged intern [PGY1 doctor], intern failed to attend'... I guess the example that I'm thinking of is a nurse had a go at me and it was written in the notes, but she'd paged the wrong person and she thought she'd paged me but got the wrong pager number, so I never got the page. And I just thought that was really unfair and then when I read the note in the file I was like, "what can you expect me to do? (2:4)

...you hear nursing staff say things like 'oh the interns [PGY1 doctors] are useless' and things like that. And so when you're coming in fresh to the ward and you're sort of greeted with that, it's very disheartening and hard to feel positive about working well with people. (3:5)

\section{Organisational structure and climate}

PGY1 doctors' main source of stress with regards to organisational structure was the arrangements for induction and handover when starting a new post. They also found that the arrangements for handing over work at the end of a shift were often inadequate, which resulted in additional unpaid overtime and concerns regarding the safety of patients out of hours.

... I find at the start of every rotation it takes at least two weeks, longer in some places than others, to get accustomed. And often it's the really stupid things that you don't know, like how I order this test or how do I refer to this person, and no-one actually thinks to hand that stuff over... (1:1)

PGY1 doctors noted that the organisation of some departments meant that it was not always possible to contact a senior colleague when required. In the early days of internship, they found this 'isolating' and 'really overwhelming'.

If you're thrown into a surgical job, all of a sudden you're on your own. Your two registrars are in theatre or admitting down in ED [Emergency Department]. It's a very isolating experience in a lot of ways, particularly early on. (1:7)

PGY1 doctors also struggled with the culture of unpaid overtime, which appeared to be an expectation of some senior colleagues, but was criticised by others.

The thing that I found really stressful in the beginning was all of the unpaid overtime... but I also felt like the word from above was that you weren't supposed to do overtime, that you wouldn't get paid for it. So you did feel a bit like a slave like that. (3:7)

\section{The individual}

During the focus groups, PGY1 doctors spoke mainly about extrinsic stressors and rarely discussed the aspects of their own and others' circumstances and personalities that may predispose to stress. When personality factors were discussed, the PGY1s reflected on how neurotic or perfectionistic personality traits influenced their ability to cope with stress.

I like to be organised; I like to know how things are going to happen. This entire year is unpredictable, so I've certainly found I've had to try and reshape the way I think just to cope with that... (1:6)

They also acknowledged feelings of guilt when they were unavailable for patients' family discussions or were required to hand over work to colleagues, supporting the hypothesis that high levels of empathy may lead to increased stress.

I sometimes felt guilty leaving the ward, like on a scheduled half day when I have personal plans and I want to go and do those things, but I also know that there are so many families [of patients] who want to chat to me... (3:8)

\section{Extraorganisational}

As with most professional roles, the demands of internship impact on the personal and social lives of individuals. There was some reluctance to discuss the nature of this impact during the focus groups, but some PGY1 doctors alluded to the ways in which work seemed to dominate their lives and impact on their health and well-being. 
You take it [anxiety] home with you and you don't actually come down off it in time for the next shift. And then you get hopped up on caffeine and then at the weekend you catch up with mates over drinks. So you go into these things that stimulate and depress you and I don't think that's very healthy... (3:8)

Some female PGY1s articulated fears that their ambitions for both a successful career and family might be incompatible.

Starting working for the first time, like, I'm 27, to try getting into a specialty program, like, when are you going to fit in family? (2:5)

\section{Refinement of the conceptual model}

The sources of stress and individual characteristics described above resonate with the 'a priori' themes provided by Michie's model of workplace stress. ${ }^{10}$ As shown in table 1, Michie's subtheme examples have been refined to more specifically represent the stressors experienced by PGY1 doctors.

After much discussion and repeated analysis, the major modification made to Michie's model by this study is the identification of an additional theme common to all of the stressors: uncertainty. The feeling of uncertainty is pervasive, and seems to generate deep-seated discontentment. It relates specifically to each of the 'a priori' themes provided by Michie's model that relate to sources of stress at work (as opposed to those relating to individual characteristics). The uncertainty described by PGY1 doctors in relation to each of the sources of stress at work identified in Michie's model is explained with examples in table 2.

\section{DISCUSSION}

This study yields new insights into the problem of workplace stress for PGY1 doctors by using, adapting and amplifying Michie's conceptual model. Through careful analysis of the data, several subthemes relating to each part of Michie's model that are most pertinent to PGY1 doctors have been identified. Some, such as long hours and work overload, are likely to apply to most professional groups. Others, such as unpaid overtime, are the targets of existing interventions designed to reduce fatigue and improve standards of care. A recent addition to primary medical training in the UK, the student assistantship, is designed to mitigate the sharp increase in clinical responsibility which newly qualified doctors have long since articulated. ${ }^{71718}$ While similar strategies exist in Australian medical education, there is little evidence indicating their effectiveness in providing either role clarity or more gradual accumulation of responsibility.

A key contributor to workplace stress in PGY1 doctors illuminated by this study is uncertainty. Uncertainty and stress have a well-established relationship, with Michie herself asserting, "situations that are likely to cause stress are those that are unpredictable or uncontrollable, uncertain, ambiguous or unfamiliar....". Similarly, the association of stress and uncertainty has been well described in reference to the practice of medicine. Previous studies have shown that junior doctors and generalists show increased anxiety due to uncertainty. ${ }^{19}$ Uncertainty has also been shown to be a major cause of mental strain for medical students and is closely associated with the fear of making mistakes. ${ }^{20}{ }^{21}$ As doctors develop their professional identities, individual conceptualisation of uncertainty has been shown to evolve from rhetoric based around personal shortcomings to one centred on the limits of evidence and scientific knowledge more broadly. ${ }^{22}$

The impact of clinical uncertainty on doctors' well-being has been explored extensively. ${ }^{1923}$ However, the uncertainty described by PGY1 doctors in this study was not confined to clinical decision-making, but permeated every aspect of their professional lives, from the components of their role to their career plans. This resonates with work from outside the medical field. For example, a study of government workers in 2001 identified links between task uncertainty, career uncertainty and 'strain' (described as 'emotional exhaustion, the core component of burnout and a common form of stress'). ${ }^{24}$ The authors concluded that increased career flexibility and career control are negatively correlated with career uncertainty and with strain. The results of this study suggest that the medical education community should seek new ways of reducing uncertainty for PGY1 doctors. For example, future work could focus on reducing career uncertainty by the provision of longer employment contracts and more tailored career advice. It would be particularly interesting to explore any difference between the career uncertainties faced by doctors in Victoria, Australia (where 1 year contracts are the norm) versus other countries such as the UK, where training contracts are usually for at least 2 years. This might help inform the evolution of training structures that acknowledge and attempt to reduce the stress experienced by PGY1 doctors.

Perhaps the most striking data in this study concerns PGY1 doctors' relationships with their colleagues at work. Many of the PGY1 doctors describe incidents that could be construed as bullying or undermining behaviour by colleagues (for example, being told that PGY1s are useless, writing damaging statements in patients' notes and being told that a senior colleague is not prepared to help when requested). The negative influence of the medical hierarchy is not unique to Australia: It has also been shown to adversely affect relationships between junior doctors and their colleagues in the $\mathrm{UK}^{18}$ and the learning experiences of Canadian medical students. ${ }^{25}$ A questionnaire study of second-year residents in the USA supports these findings, with $93 \%$ of the 1277 respondents experiencing 'at least one incident of perceived mistreatment ${ }^{26}{ }^{26}$ Future research could focus on exploring whether the current hierarchical model of leadership within medicine is still fit for purpose, and if so, what can be done to mitigate its negative influence on the stress experienced by PGY1 doctors. 


\begin{tabular}{|c|c|c|c|c|c|c|}
\hline 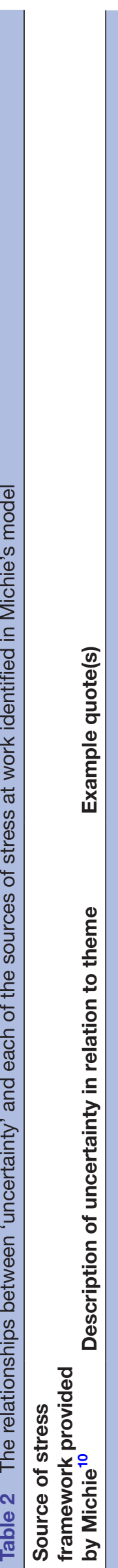 & \multicolumn{2}{|c|}{ 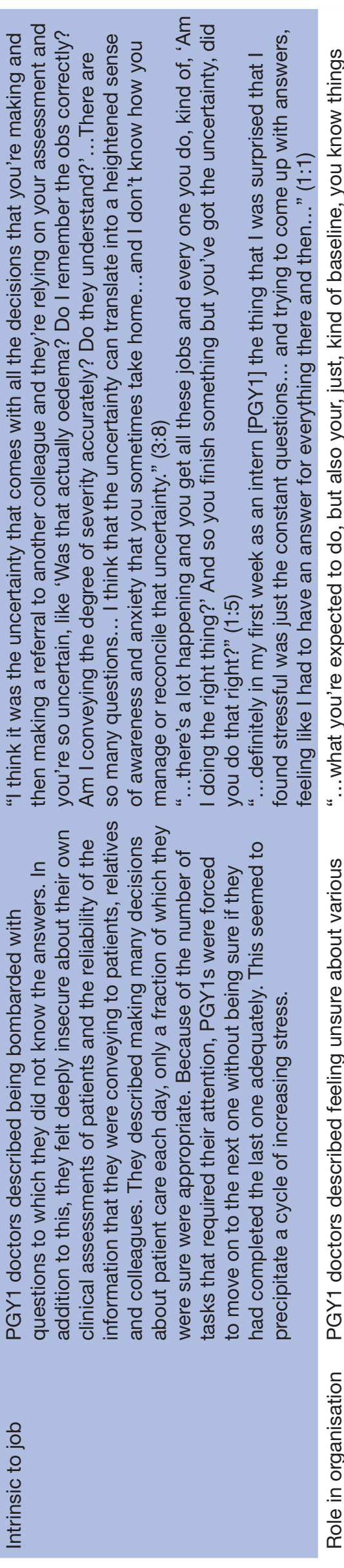 } & 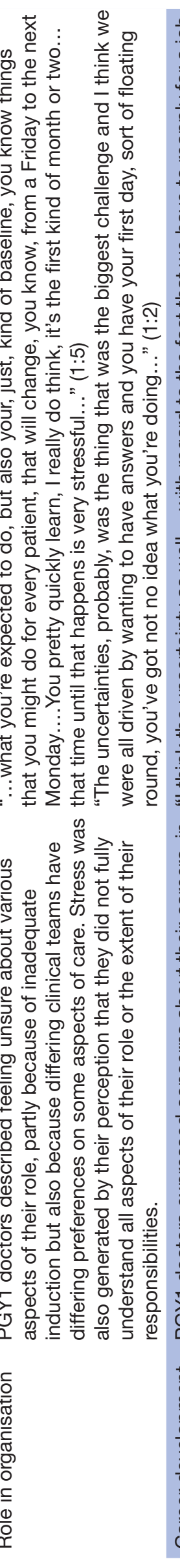 & 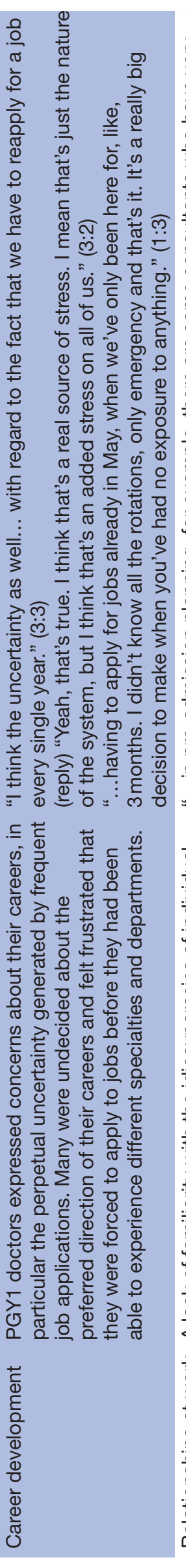 & 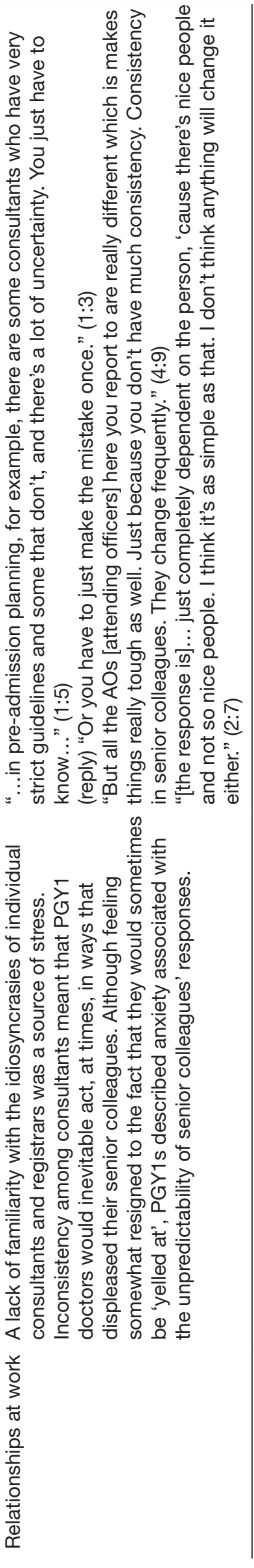 & \\
\hline
\end{tabular}




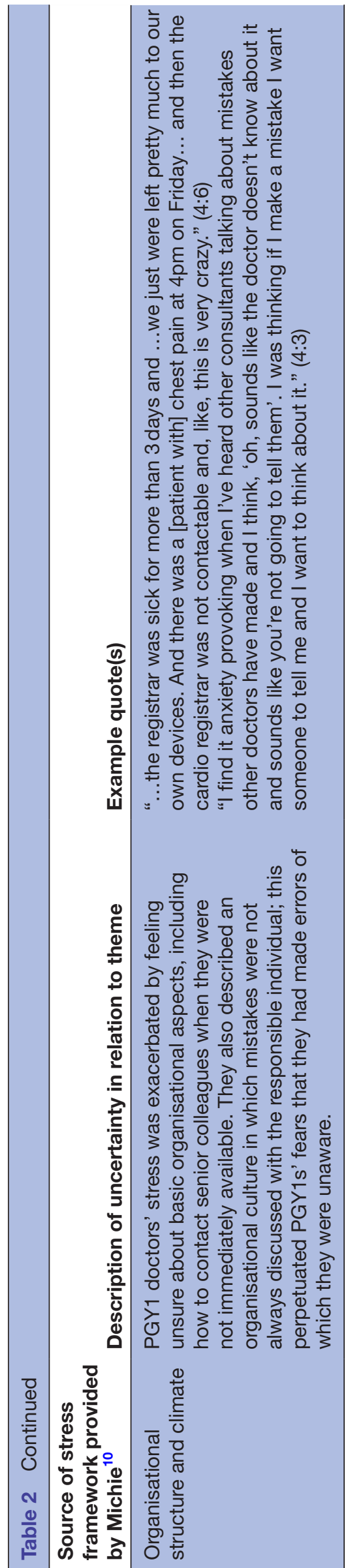

Limitations

This study used the principles of template analysis to produce a bespoke version of Michie's workplace stress model that encapsulates the stressors applicable to PGY1 doctors. It is, however, limited by a number of important factors. The first is that we did not observe the participants within their workplace but instead relied on retrospective accounts and reflections that may have been influenced by subsequent experiences or merely the passage of time. As with all studies that use volunteers, attendees at the focus groups may have been those with particularly strong views or negative experiences. Similarly, the views, beliefs and experiences of the research team (particularly VT) are likely to have impacted on both data collection and analysis.

Perhaps the most significant limitation relates to the method of data collection. A purposive sampling technique was used to select the hospitals involved in the study, but was not applied to the selection of individual interns (relying instead on volunteers). A more sophisticated sampling technique incorporating individual factors such as age, gender and undergraduate versus graduate entry to medical school may have enriched the data further. While focus groups benefit from allowing participants to discuss ideas and react to the suggestions and experiences of others, it is likely that this forum limited the willingness of PGY1 doctors to discuss either individual personality traits that may predispose to stress or its impact on their personal lives. This limitation may have been exaggerated by the size of the groups (between 7 and 14 participants) and the fact that group participants were likely to have known each other. Such personal reflections may be more effectively elicited using individual interviews or audio diaries. While the themes discussed in this paper recurred, claims of theoretical saturation are not possible as participant numbers were limited by time scale and availability of PGY1 doctors.

\section{CONCLUSION}

This paper has explored PGY1 doctors' views of their workplace stressors. Using template analysis, we have modified and amplified Michie's framework of sources of stress at work. Modifications include the addition of a common theme (uncertainty) and the incorporation of subcategories of the major themes as they relate to PGY1 doctors' stress. Future work might usefully focus on exploring ways to reduce stress at each of these levels and in particular reducing the uncertainties faced by PGY1 doctors on a daily basis. The modified version of Michie's framework presented within this paper provides a springboard for further research into uncertainty and stress across all grades of doctors. It could also be used by policy-makers when considering the impact of decisions on the psychological distress of the medical workforce. 
the local organisers at each health service where the focus groups were hosted; namely, A/ Prof Erwin Loh (Chief Medical Officer) and Alana Gilbee (Clinical Skills Co-ordinator) at Monash Health, Dr Linda Danvers (Deputy Director of Medical Services) and Dr Jaycen Cruickshank (Supervisor of Intern Training) at Ballarat Health Services, and Dr Peter Bradford (Executive Director Clinical Governance and Medical Services) and Lynne Denby (Medical Education Manager) at Melbourne Health. Finally, we thank all intern participants of the focus groups.

Contributors VRT, SES and ADF designed the study. VRT conducted all focus groups with the help of either LR or ADF. VRT and SES analysed the data and presented the initial findings to $L R$ and ADF for discussion and modification. VRT and ADF wrote the manuscript which all authors reviewed and amended prior to submission

Funding This work was funded by the Postgraduate Medical Council of Victoria (Research Grant 2014: Junior Doctor Wellbeing and Support) but they had no involvement in study design, data collection or analysis, writing of the manuscript or the decision to submit for publication.

Competing interests None declared.

Ethics approval Monash University Human Resources Ethics Committee.

Provenance and peer review Not commissioned; externally peer reviewed.

Data sharing statement № additional data are available.

Open Access This is an Open Access article distributed in accordance with the Creative Commons Attribution Non Commercial (CC BY-NC 4.0) license, which permits others to distribute, remix, adapt, build upon this work non-commercially, and license their derivative works on different terms, provided the original work is properly cited and the use is non-commercial. See: http://creativecommons.org/ licenses/by-nc/4.0/

(C) Article author(s) (or their employer(s) unless otherwise stated in the text of the article) 2017. All rights reserved. No commercial use is permitted unless otherwise expressly granted.

\section{REFERENCES}

1. Brazeau CM, Shanafelt T, Durning SJ, et al. Distress among matriculating medical students relative to the general population. Acad Med 2014;89:1520-5.

2. Dyrbye LN, Thomas MR, Massie FS, et al. Burnout and suicidal ideation among U.S. medical students. Ann Intern Med 2008;149:334-41.

3. Elliot LTJ, Norris S. The mental health of doctors: a systematic literature review. Beyondblue 2010.

4. Wallace JE, Lemaire JB, Ghali WA. Physician wellness: a missing quality Indicator. Lancet 2009;374:1714-21.

5. Beyondblue. National Mental Health survey of doctors and medical students. Australia: Beyondblue, 2013.

6. Honney K, Buszewicz M, Coppola W, et al. Comparison of levels of depression in medical and non-medical students. Clin Teach 2010;7:180-4.
7. Illing J, Morrow G, Kergon C, et al; How prepared are medical graduates to begin practice? A comparison of three diverse UK medical schools. DU: Final report to GMC, 2008.

8. Firth-Cozens J. Emotional distress in junior house officers. Br Med $\mathrm{J}$ 1987;295:533-6.

9. Facey AD, Tallentire V, Selzer RM, et al. Understanding and reducing work-related psychological distress in interns: a systematic review. Intern Med J 2015;45:995-1004.

10. Michie S. Causes and management of stress at work. Occup Environ Med 2002;59:67-72.

11. Murphy L. Occupational stress management: current status and future directions. In: Cooper CL, Rousseau CL, eds. Trends in Organisational Behavior. New York: John Wiley and Sons, 1995:1-14.

12. Babatunde A. Occupational stress: a review on conceptualisations, causes and cure. Econom Insights - Trends Chall 2013:73-80.

13. PMCV. Postgraduate Medical Council of Victoria. 2015 http://www. pmcv.com.au/ (accessed 6 Apr 2015).

14. Barbour RS. Making sense of focus groups. Med Educ 2005;39:742-50.

15. Kitzinger J. Qualitative Research: introducing focus groups. BMJ 1995;311:299-302.

16. King N, Template analysis. In. Cassell GSC, Qualitative methods and analysis in organizational research: a practical guide. Thousand Oaks, CA: Sage Publications Ltd, 1998:118-134.

17. Prideaux D, Worley P, Bligh J. Symbiosis: a new model for clinical education. Clin Teach 2007;4:209-12.

18. Tallentire VR, Smith SE, Skinner J, et al. Understanding the behaviour of newly qualified doctors in acute care contexts. Med Educ 2011;45:995-1005.

19. Bovier PA, Perneger TV. Stress from uncertainty from graduation to retirement-a population-based study of Swiss physicians. J Gen Intern Med 2007;22:632-8.

20. Nevalainen MK, Mantyranta T, Pitkala KH. Facing uncertainty as a medical student--a qualitative study of their reflective learning diaries and writings on specific themes during the first clinical year. Patient Educ Couns 2010;78:218-23.

21. Smith SE, Tallentire VR, Cameron HS, et al. The effects of contributing to patient care on medical students' workplace learning Med Educ 2013;47:1184-96.

22. Lingard L, Garwood K, Schryer CF, et al. A certain art of uncertainty: case presentation and the development of professional identity. Soc Sci Med 2003;56:603-16.

23. Schor R, Pilpel D, Benbassat J. Tolerance of uncertainty of medical students and practicing physicians. Med Care 2000;38:272-80.

24. Ito JK, Brotheridge CM. An examination of the roles of career uncertainty, flexibility, and control in predicting emotional exhaustion. $J$ Vocat Behav 2001;59:406-24.

25. Allen D, Wainwright M, Mount B, et al. The wounding path to becoming healers: medical students' apprenticeship experiences. Med Teach 2008;30:260-4.

26. Daugherty SR, Baldwin DC, Rowley BD. Learning, satisfaction, and mistreatment during medical internship: a national survey of working conditions. JAMA 1998;279:606-7. 